\title{
The Evolution of Wide-Area DInSAR: From Regional and National Services to the European Ground Motion Service
}

\author{
Michele Crosetto ${ }^{1}\left(\mathbb{D}\right.$, Lorenzo Solari ${ }^{1,2, *}{ }^{(0)}$, Marek Mróz ${ }^{3}\left(\mathbb{D}\right.$, Joanna Balasis-Levinsen ${ }^{4}$, \\ Nicola Casagli ${ }^{5}{ }^{\circ}$, Michaela Frei ${ }^{6}$, Anneleen Oyen ${ }^{7}$, Dag Anders Moldestad ${ }^{8}$, Luke Bateson ${ }^{9}$, \\ Luca Guerrieri ${ }^{10}$, Valerio Comerci ${ }^{10}{ }^{1}$ and Henrik Steen Andersen ${ }^{2}$ \\ 1 Centre Tecnològic de Telecomunicacions de Catalunya (CTTC/CERCA), Geomatics Division, Av. Gauss, 7, \\ 08860 Castelldefels, Spain; michele.crosetto@cttc.cat \\ 2 European Environment Agency, Kongens Nytorv 6, 1050 Copenhagen, Denmark; \\ Henrik.Andersen@eea.europa.eu \\ 3 Institute of Geodesy and Civil Engineering, University of Warmia and Mazury in Olsztyn, \\ ul. Oczapowskiego 1, 10-719 Olsztyn, Poland; marek.mroz@uwm.edu.pl \\ 4 Agency for Data Supply and Efficiency, Rentemestervej 8, 2400 Copenhagen, Denmark; jofle@sdfe.dk \\ 5 Department of Earth Sciences, University of Firenze, Via La Pira 4, 50121 Firenze, Italy; nicola.casagli@unifi.it \\ 6 Bundesanstalt für Geowissenschaften und Rohstoffe, Stilleweg 2, 30655 Hannover, Germany; \\ Michaela.Frei@bgr.de \\ 7 Rijkswaterstaat, Ministerie van Infrastructuur en Waterstaat, Postbus 2232, \\ 3500 GE Utrecht, The Netherlands; anneleen.oyen@rws.nl \\ 8 Norsk Romsenter, Drammensveien 165, 0277 Oslo, Norway; dag.anders.moldestad@spaceagency.no \\ 9 British Geological Survey, Nicker Hill, Keyworth, Nottingham NG12 5GG, UK; lbateson@bgs.ac.uk \\ 10 Istituto Superiore per la Protezione e la Ricerca Ambientale-ISPRA, Via Vitaliano Brancati, \\ 48-00144 Roma, Italy; luca.guerrieri@isprambiente.it (L.G.); valerio.comerci@isprambiente.it (V.C.) \\ * Correspondence: lorenzo.solari@cttc.cat
}

Received: 25 May 2020; Accepted: 23 June 2020; Published: 25 June 2020

\begin{abstract}
This study is focused on wide-area deformation monitoring initiatives based on the differential interferometric SAR technique (DInSAR). In particular, it addresses the use of advanced DInSAR (A-DInSAR) techniques, which are based on large sets of synthetic aperture radar (SAR) and Copernicus Sentinel-1 images. Such techniques have undergone a dramatic development in the last twenty years: they are now capable to process big sets of SAR images and can be exploited to realize a wide-area A-DInSAR monitoring. The study describes several initiatives to establish wide-area ground motion services (GMS), both at county- and region-level. In the second part of the study, some of the key technical aspects related to wide-area A-DInSAR monitoring are discussed. Finally, the last part of the study is devoted to the European ground motion service (EGMS), which is part of the Copernicus land monitoring service. It represents the most important wide-area A-DInSAR deformation monitoring system ever developed. The study describes its main characteristics and its main products. The end of the production of the first EGMS baseline product is foreseen for the last quarter of 2021.
\end{abstract}

Keywords: SAR; advanced DInSAR; Copernicus Programme; European ground motion service; national ground motion services

\section{Introduction}

Differential interferometric SAR (DInSAR) is a remote sensing technique, based on satellite radar imagery, for the deformation measurement and monitoring of land, structures and infrastructures. 
This study mainly refers to advanced DInSAR (A-DInSAR) techniques, which are based on large stacks of SAR images and appropriate tools to process them [1-3]. A-DInSAR has several distinctive characteristics. It enables the measurement from space of small displacements, at millimeter-scale. It covers wide areas with a relatively high spatial measurement density. It provides a systematic temporal deformation monitoring. It can measure past deformation phenomena, exploiting the SAR image historical archives. It is a non-invasive technique and it enables a potential reduction of the amount of ground-based deformation observations, thus allowing economic savings.

In the last two decades, the A-DInSAR techniques have undergone a dramatic development. This is mainly due to three main factors. The first key factor is SAR data availability, a conditio sine qua non for any SAR-based technique. The development of the first decade of A-DInSAR was based on medium-resolution C-band data from ERS-1/2, Envisat and Radarsat-1. A-DInSAR took a major step forward with the advent of very high-resolution X-band data coming from TerraSAR-X and COSMO-SkyMed. A further most significant improvement was the launch of the two Sentinel-1 satellites, equipped with C-band sensors. Sentinel-1 improved the existing data acquisition performances in terms of area coverage, revisiting time and data throughput, considerably increasing the A-DInSAR deformation monitoring potential. Sentinel-1 is supported by an open-source distribution strategy allowing the user community to expand enormously $[4,5]$.

The second factor is the spectacular increase of the A-DInSAR data processing and analysis techniques. Since the publication of the first A-DInSAR technique [6,7], dozens of new techniques have been proposed, which concern all components of the A-DInSAR processing chain. For a general review see [2]. Such techniques have considerably improved the A-DInSAR performance in terms of measurement point (MP) density, quality and reliability. The third factor is the increase of the A-DInSAR computational capability. The data acquisition capability of SAR sensors has always been overwhelmingly higher than our collective capacity to process SAR data. Several groups have worked on the exploitation of advanced computational resources, using, e.g., parallel computing, virtual machines, distributed computing architectures, etc. The net result is that wide-area A-DInSAR deformation monitoring has been widely demonstrated in the last years, e.g., see $[8,9]$.

The main consequence of the above three factors is the A-DInSAR capability to cover wide areas. Thanks to this, A-DInSAR is moving from local deformation studies, typically at the size of single image frames, to wide-area multiple-frame monitoring projects, thus exploiting the full potential of the satellite-based SAR data [10-12]. Some countries have implemented nationwide A-DInSAR-based ground motion services (GMS). In some cases, these services are carried out at regional scale. In addition, a European initiative started in 2016 to implement a A-DInSAR-based European ground motion service (EGMS) and to provide consistent A-DInSAR data at a continental scale [13]. This service is currently under development.

This study is organized as follows. First, a description of some important country-wide and region-wide A-DInSAR deformation monitoring services is provided. This is followed by the discussion of the key technical characteristics of wide-area A-DInSAR monitoring. This section includes some relevant deformation monitoring examples coming from the GMSs. Finally, the main characteristics of the EGMS are described, followed by some conclusive remarks.

\section{An Overview of Ground Motion Services in Europe}

Taking advantage of the factors described in the previous section, there are several GMS initiatives ongoing. As of May 2020, Norway and Germany finalized the production of nationwide interferometric services based on Sentinel-1 images. Netherlands is finalizing the implementation of a GMS, while Denmark is working to setup one there. In Italy, Tuscany, Valle d'Aosta and Veneto regions launched their Sentinel-1-based monitoring services. Other European countries are testing, developing and discussing the feasibility of national GMSs. In the following section we review the operational nationwide and region-wide GMSs. 


\subsection{Special Plan of Remote Sensing of the Environment-Italy}

The first national GMS, precursor of those based on Sentinel-1, was the Italian Special Plan of Remote Sensing of the Environment, launched in 2007 and aimed to cover the whole Italian Peninsula with interferometric data derived from ERS 1/2, Envisat and COSMO-SkyMed SAR images. The project was financed and managed by the Italian Ministry of the Environment.

Between 2008 and 2016, ERS 1/2 (spanning the period 1992-2001), Envisat (spanning the period 2002-2010) and COSMO-SkyMed (spanning the period 2011-2016) images were collected and processed by means of A-DInSAR approaches. The PSP (persistent scatterer pairs [14]), the PSInSAR [6,7] and the SqueeSAR [15] algorithms were applied to analyze more than 20,000 images in both ascending and descending orbits. A detailed explanation of the processing approach is provided by Costantini et al. [16]. The data were made available on a dissemination platform allowing the users to access deformation maps and time series, but without a direct data download. The platform evolved over time and is still active and available at [17]. It now grants the possibility of obtaining data only upon request. Guidelines for the correct interpretation of interferometric products are provided to the users [18]. Academia, national institutions, research centers and regional authorities were involved in the validation of the data. The validation was carried out on the basis of: i) GNSS deformation measurements; ii) precise optical leveling and iii) field evidences collected by regional geological surveys. See Di Martire et al. [19] for an example of a validation approach designed for the data of this service.

The implementation of a new national GMS based on Sentinel $(1 \mathrm{~A}, \mathrm{~B})$ and COSMO-SkyMed data, is in progress as part of the Italian space economy strategic plan [20] This service will be realized taking into account the user requirements and needs collected by consolidated communities of GMS users, including the networks of geological surveys and environmental agencies (national and regional) and the national system of civil protection. The user community clearly recommended the consistency between this national service and the already operational regional services (see Section 2.6). The service will provide velocity maps calibrated with global navigation satellite system (GNSS) data for deferred and near-real time activities. On demand services will be carried out to address specific hazardous areas or events, e.g., seismic or volcanic emergencies.

\subsection{InSAR Norway}

Norway is the first example of national GMS based on Sentinel-1 images to be freely distributed to the general public. The service, InSAR Norway, was launched in November 2018 and is currently operated by the geological survey of Norway, with co-funding from the Norwegian space center and the Norwegian water and energy directorate. InSAR Norway grew out of previous regional activities using first ERS-1/2 and Envisat and later Radarsat-2 data [21]. Norway is a sparsely populated and mountainous country where in situ data are sometimes difficult to gather and where InSAR products are relevant for landslide detection and mapping. Many landslides were already detected thanks to the previous InSAR results, but the Sentinel-1 coverage eased and enhanced this activity. Over 100 new potential landslides were identified in the first months after the official launch of the service [22].

The satellite tracks of Sentinel-1 approach each other near the poles, resulting in a large overlap in Norway. Two datasets with full coverage of the nation are produced for both ascending and descending tracks by implementing a full resolution PSI (Persistent Scatterer Interferometry) approach. A third overlapping dataset is delivered for the northern part of Norway. Data processing is done on a high-performance computing cluster using software mainly developed by NORCE (Norwegian research center). The reference processing units is a $5 \times 5-\mathrm{km}$ tile with a local reference. The tiles are mosaicked without the use of a global navigation satellite systems (GNSS) network. Before putting the tiles together for the nationwide final product, the tiles are adjusted so that the peak of the velocity histogram is zero $\mathrm{mm} / \mathrm{yr}$. This means that the deformation map contains only relative and local deformation without the small-scale components. To avoid problems with snow, the processing stack includes only images from June to October. As of May 2020, the baseline product (2015-2018) and 
one update (2015-2019) were produced and made available through a dedicated web geographic information system (WebGIS, [23]).

All the deformation maps and time series are distributed via a free and open dissemination platform. The user can visualize the single MP and its time series, exporting it as *.svg or *.csv file. This operation can be performed individually or on a group of MP selected by means of a polygon drawn by the user. In addition to the download functionality provided by the WebGIS, an application programming interface (API) is available for access to the data. The dissemination platform includes also: (i) Radarsat-2 data covering the portions of Norway with the highest landslide risk and referred to the period 2009-2018; (ii) bedrock maps; (iii) Quaternary geological maps; (iv) catalogs of unstable slopes; and (v) links to user guides and data description [24,25].

\subsection{BodenBewegungsdienst Deutschland-Germany}

One year after the launch of InSAR Norway, Germany presented its ground motion service Germany (BodenBewegungsdienst Deutschland-BBD). The service was designed by the Federal Institute for Geosciences and Natural Resources (BGR) in communication with the user community, federal geological surveys, land surveying agencies, small and medium-sized enterprises and research institutions. Before the start of the production cycle, user workshops and interministerial meetings were organized to identify and collect the main user requirements [26]. In addition, a user survey based on a questionnaire was conducted to support the identification of the required applications and to rank the importance of specific processing features.

The BBD is based on Sentinel-1 images (both 1A,B) contracted for processing to the German Aerospace Center (DLR) after open procurement procedure. The SAR dataset covers the timespan from November 2014 to March 2019 and consists of 21 ascending and 20 descending Interferometric Wide frames. Sentinel-1 images are processed by means of a wide area PSI approach [27]. Numerical weather forecast data are used to mitigate the troposphere effect in the interferograms and thus, increase the precision of the results [28] A modified version of the 3-arc-second SRTM C-band digital elevation model (DEM) [29] was used to estimate and subtract the topographic phase from the interferograms. Since the BBD is produced from adjacent and overlapping frames, a mosaicking approach is applied to produce a homogeneous national-scale deformation map. The mosaicked dataset is subsequently calibrated by using a nationwide GNSS network (SAPOS $\left.{ }^{\circledR},[30]\right)$.

The data are distributed as GNSS-calibrated deformation maps and freely available on the BGR WebGIS [31]. Users can download data within a search window of maximum $400 \mathrm{~km}^{2}$; larger download areas are available upon request. Terms of use and a data disclaimer are available in the BGR website [32,33].

The BBD products are quality controlled following three concepts: (i) internal quality control during processing; (ii) verification with GNSS time series; and (iii) plausibility assessment by using thematic data (geologic maps, land cover maps) and ground truthing. In addition, several pilot studies started after the first data delivery in 2018. The pilot studies were carried out by the state and federal geological and geodetic surveys and by ministries. Beside product validation and verification, user uptake and capacity building were the major goals to reach for such pilot studies.

\subsection{Danish Ground Motion Service}

The Agency for Data Supply and Efficiency (SDFE), part of the Danish Ministry of Climate, Energy and Utilities, is working towards the development of a nationwide GMS for Denmark. The service is to be full, free and open to all interested end-users. The work is currently in a "preoperational" phase since two consecutive nationwide maps were produced, but the data are not yet available via a fully open WebGIS platform. Rather, it can be accessed, worked with and downloaded for free once log-in information to the platform was provided by SDFE. 
The nationwide service was realized as a response to a growing interest for such data over Denmark. This was made possible on the basis of several pilot studies over smaller areas, end-user workshops with participants from both the public and private sectors, as well as case studies.

To date, nationwide deformation maps were published in 2018 and 2019 based on all available Sentinel-1 data from 2014 and until the respective year. The deformation maps are derived by means of a homogeneous persistent and distributed scatterers interferometry (PSI + DSI) algorithm: SqueeSAR [15]. In addition to the line of sight (LOS) deformation maps, SDFE is distributing: (i) GNSS-calibrated deformation maps [34]; (ii) hotspots of PS/DS with anomalous temporal behavior; and iii) east-west horizontal and vertical deformation rates. The latter are provided in an $80 \mathrm{~m}$ by $80 \mathrm{~m}$ grid. The vertical rates are calibrated with GNSS data (coming from a national network managed by SDFE, [35]) and an uplift model [36].

The deformation maps are distributed free of charge as part of the SDFE's efforts towards establishing the operational service. As such, important goals within this phase are to increase the knowledge level on satellite-based deformation monitoring, including possibilities and limitations with such data, and to learn about end-user requirements for the service. The SDFE has written two reports in Danish to help bridging the gap between InSAR experts and potential end-users of such data in Denmark. The first report introduces the InSAR technique; it includes examples of use cases, a frequent asked questions section and references to literature. The other describes the delivered products and guides the user to start working with the InSAR data. It also contains a data disclaimer. The users gain access to the reports and to a WebGIS where the data can be visualized, investigated and downloaded.

SDFE validates the data in several ways. One uses SDFE's network of corner reflectors, which have been levelled continuously, after which the two contemporary and independent datasets are compared. Another investigates the correlation between the GNSS data and the GNSS-calibrated vertical deformation rates. Furthermore, end-users in the private industry are doing independent validation studies using their own levelling data.

\subsection{Dutch Ground Motion Service}

Rijkswaterstaat (RWS-Ministry of infrastructure and water management) is finalizing the implementation of a GMS based on Sentinel-1 data covering the Netherlands. The trajectory towards the Dutch service started in 2017. The first step was a market consultation aimed to evaluate the technical and economic feasibility of such a service. The input of national and international A-DInSAR data providers was taken into account for the creation of the tender specifications. The tender was published by RWS and by the Ministry of economic affairs and climate in October 2018. The Netherlands will launch its nationwide deformation service, entitled "InSAR based ground motion service for the Dutch built environment" in summer 2020.

The aim of the Dutch ground motion service is to provide a national base map for height change obtained through A-DInSAR. Streamlined data format and well-defined data quality are key for such data sets. Furthermore, RWS have a nationwide area to manage and therefore the choice for a central ground motion service is straightforward.

The nationwide service will provide PS and DS results in two different data levels from all tracks covering the (European) Dutch territory:

- First Level (defined as Level 2): LOS deformation map in ascending and descending orbits connected to the Dutch GNSS network composed of permanent stations part of the AGRS-NL [37] and NETPOS [38] networks;

- Second Level: (1) Level 3a, a gridded dataset in which all the PS/DS points with heights estimated on ground level (defined by the actual height model of the Netherlands, AHN, [39]) are aggregated to a raster with grid size of maximum $200 \mathrm{~m}$; (2) Level 3b, a vector set in which all the PS/DS points with geo-localization on a set of predefined civil objects and highway sections are aggregated with a given polygon set. Both sets are decomposed in the vertical and east-west horizontal components. 
The Dutch GMS will be updated twice per year and will be a free and open service. The data will become available through the RWS regular data publication channels. Options for hosting the Dutch public viewer are still being investigated at the moment of writing. However, an internal viewer has already been developed.

The products of the Dutch service are being validated on different levels: (i) the A-DInSAR provider has to deliver an internal quality report in which has to be demonstrated that the delivered product meets the technical requirements, (ii) internally RWS performs a quality control on the process and the delivered data itself and (iii) an independent external organization performs a thorough quality control of the delivered data. The data are cross-validated with external datasets: (i) GNSS time series obtained by stations not used to produce the Dutch GMS, (ii) levelling data from the Dutch height reference network (Amsterdam ordnance datum-NAP, [40]), (iii) time series from the nationwide network of corner reflectors and iv) the AHN.

\subsection{Sentinel-1 Monitoring Services_Italian Regions}

Tuscany (central Italy), Valle d'Aosta (northwestern Italy) and Veneto (northeastern Italy) have implemented, with different timing, regional monitoring services entirely based on Sentinel-1-derived A-DInSAR products. The services are considered to be near-real time monitoring systems according to the Prime Minister Decree of 27 February 2004. Back in 2016, Tuscany launched the first example of such a service, followed in 2018 by Valle d'Aosta and in 2019 by Veneto.

The monitoring services rely on two different temporal baselines: deferred time mapping and near-real-time monitoring, the latter defined as the continuous processing of Sentinel-1 images coupled with a time series data mining algorithm. The first activity produces databases of active ground motion as deformation snapshots at a certain time. The outputs are meant for land planning and geohazard mapping purposes. The second activity generates maps highlighting all the measurement points with anomalous behavior for every new processing cycle, i.e., with acceleration or deceleration of motion in a defined temporal window. This activity produces databases of anomalous PSs (aPSs). Such data are relevant for risk management and civil protection activities: in this monitoring approach satellite radar data feed a decision chain for hydrogeological risk mitigation. Strategies for risk reduction can start with satellite radar data, prioritizing those instabilities that represent a major threat and are deemed to be most urgent.

The analysis of Sentinel-1 images follows a common approach, but the data processing is independent between the three regions. The first phase is devoted to the generation of the deformation maps at regional scale by means of a parallelized SqueeSAR approach [15]. The first deformation map acts as baseline for the future updates. Around every 12 days new deformation maps are derived; then, a novel data mining algorithm is applied to identify the aPS. Time series of each measurement point are systematically analyzed to detect any change in the deformation pattern. In summary, the algorithm searches for any trend change higher than a predefined value within a temporal window, see for details [41].

Two products are regularly delivered for all the three regions: standard deformation maps with velocities along the LOS with time series and advanced aPSs maps with time series. Only for Tuscany, the information on significant and persistent aPSs is routinely delivered to regional authorities in the form of monitoring bulletins.

For the Tuscany region, deformation maps can be accessed by all interested users in an open format, while access to the anomalous point database is restricted to regional authorities. The deformation maps are uploaded in a WebGIS developed by the LAMMA consortium [42]. Users are free to interact with the data and download the deformation maps without any spatial restriction. Users have access to a simple map creation tool and can upload their own ancillary dataset if needed. Guidelines and data disclaimers are available as well $[43,44]$.

The interferometric results are validated through field surveys and comparison with external information or in situ measurements. The Tuscany region in collaboration with the University of 
Firenze developed a standardized field survey procedure which is aimed to validate the interferometric results where the highest deformation rates and trend changes are recorded [45]. The procedure was already applied in different urban contexts affected by landslides or subsidence [46].

Table 1 provides a summary of the main characteristics of the operational GMS presented in the previous chapters.

Table 1. Summary of the main characteristics of operational GMS at national and regional scale in Europe. The GMS are listed in alphabetical order.

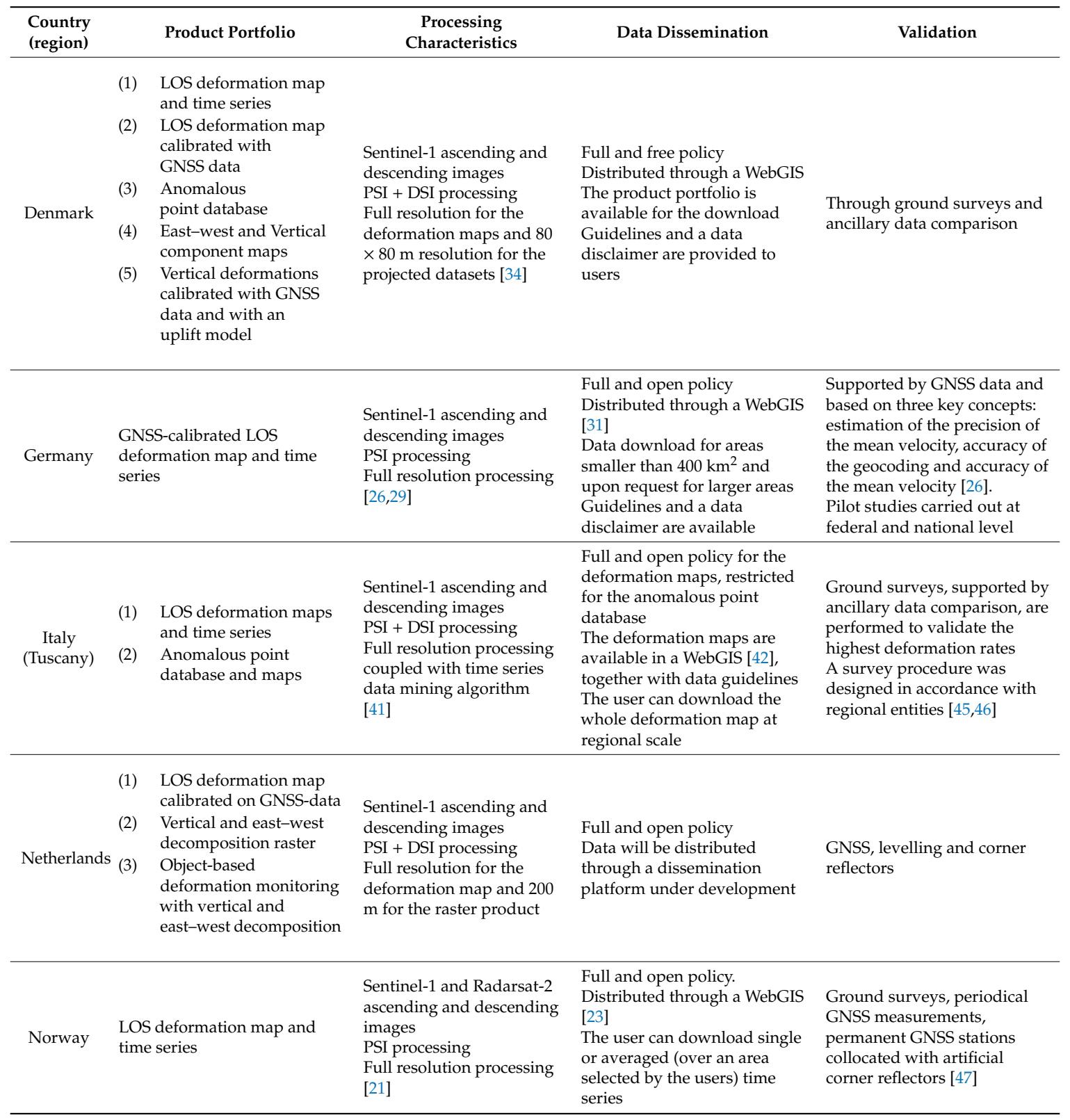

\section{Technical Aspects for Wide-Area DInSAR Processing}

In this section, some of the most important technical aspects of the A-DInSAR techniques are reviewed. Emphasis is given to the aspects relevant to wide-area deformation monitoring, as derived from the experience with national and regional GMSs. Some examples extracted from the dissemination platforms of operational GMS are proposed. 


\subsection{SAR Data Availability}

At the time of writing this study, there are more than 15 active spaceborne SAR sensors, and several new missions will be launched in the forthcoming years. Therefore, SAR data acquisition is guaranteed. The most important SAR sensors for the wide-area services are Sentinel-1A and 1B. These sensors provide a reliable global coverage from two different look angles and a free and open data policy. From September 2016 the constellation grants a revisit time of six days over Europe. This makes an operational Europe-wide displacement monitoring feasible. Provided that follow-on satellites (Sentinel-1C and 1D) are under development, Sentinel-1 data acquisition is guaranteed for at least the next decade.

\subsection{Spatial Sampling of Measurements}

Over wide areas, the A-DInSAR spatial sampling is uneven. In fact, A-DInSAR can only measure deformation over the targets that provide a sufficient interferometric phase quality. This is not known before performing the A-DInSAR analysis. The sampling density is usually low in vegetated, forested and smooth surfaces, etc. Snow coverage, construction works, street re-pavement are examples of phenomena that can cause a complete or temporary loss of MP. In the A-DInSAR processing, two main types of targets can be considered. The persistent scatterers (PS) are usually point-like dominating targets that maintain a stable response over time to the SAR microwaves [6,7]. The PSs are usually dense over structures, infrastructures, antennas, poles, conducts, exposed rocks, etc. The distributed scatterers (DS) correspond to multiple scatterers that individually provide a lower response to microwaves, but that collectively can provide a sufficient phase quality to derive reliable deformation measurements [15]. DSs can be found in non-cultivated lands, desert areas, scattered outcrops, debris-covered areas, etc. While there are A-DInSAR processing techniques that are only focus on PSs or DSs, in the last decade several hybrid approaches have been proposed, which make use of both PSs and DSs [14,15,48-50].

Figure 1 provides an example of the dependency of MP density with land cover. The inputs of this analysis are two: a deformation map from the WebGIS of the Tuscan GMS and the Corine land cover 2018 map (CLC2018) [51]. The deformation map was derived by using the SqueeSAR approach described in Chapter 2.6 and by Raspini et al. [41]; the temporal coherence threshold was fixed to 0.85 . The CLC2018 has a minimum mapping unit of 25 hectares and a minimum mapping width of $100 \mathrm{~m}$. In Tuscany, the predominant land cover classes are agriculture and vegetated areas/forests (see the pie chart in the inset $C$ of Figure 1).

The bar chart in Figure 1B well describes the dependency of MP density with land cover. As expected, the urban and anthropic surfaces show the highest value of MP density. The density of the three classes referred to the urban fabric (CLC2018 class no. 111, 112 and 121) have an average above $400 \mathrm{MP} / \mathrm{km}^{2}$. The lower limit of class 112 and 121 is related to the mapping resolution of the CLC2018; in this case, natural surfaces are incorporated in the discontinuous fabric, producing a lower point density. The same consideration is valid for the agricultural CLC2018 classes (241 to 244). On average, such surfaces have point density below $50 \mathrm{MP} / \mathrm{km}^{2}$, but there are some upper outliers which can be related to the presence of groups of buildings within a CLC mapping unit (e.g., see the small village of "Lecore" in Figure 1A). It is interesting to notice that the classes related to the presence of marshes and water bodies (CLC2018 class no. 411 to 521) are not null. This is again connected to the resolution of the reference land cover layer. The Arno River, mapped as a single polygon referred to the CLC2018 class 511 "water courses", is crossed by a bridge which is an ideal reflector (Figure 1A). In this case, the PS and DS referred to the bridge fall within the CLC20218 class 511. The same consideration is true for the artificial lake of the Renai Park, where some sparse buildings act as PS/DS targets. 

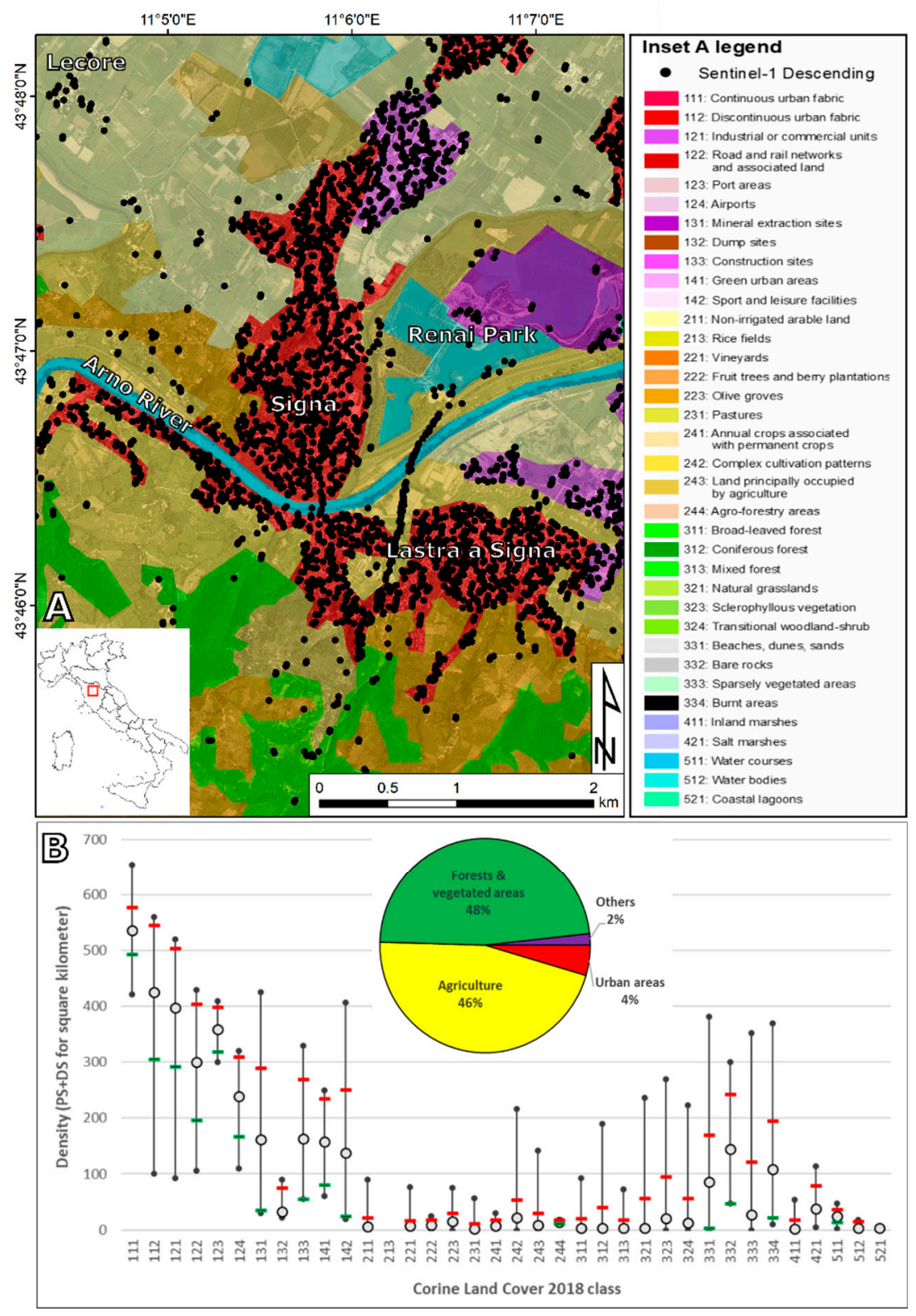

Figure 1. (A) Sentinel-1 measurement point (MP) density with respect to the land cover in one sector of the Tuscany region, central Italy. (B) Minimum temporal coherence of the MPs is 0.85 . Bar chart which correlated Corine land cover classes and MP density for the Tuscany region. Gray dots represent the median value for each class, the black dots the minimum and maximum density values, the red and green lines represent the median plus and minus the standard deviation, respectively. The pie chart is referred to the spatial coverage of Corine land cover classes for the Tuscany region. The background image for inset A and B is an AGEA orthophoto 2016.

\subsection{Deformation Measurement Products}

There are two main products of a A-DInSAR data analysis. Both are vector products whose information refers to the selected MPs and is relative to a reference point. The first one is the deformation velocity map. This is a product that contains, for each MP, the estimated deformation velocity over the observed period. This is a single parameter derived from many observations (the number the used SAR images): it is more precise and robust than the deformation time series. The latter ones provide, for each MP, the deformation history over the observed period. They contain one deformation 
estimate per each SAR acquisition date. This product is important to study the kinematic history of the observed phenomena.

\subsection{Product 3D Location}

An additional A-DInSAR information is the so-called topographic error map. It displays the height of the given MP with respect to the reference Digital Elevation Model used in the A-DInSAR processing. This product is fundamental for the 3D positioning and hence the interpretation of the MPs. The 3D location is known with an uncertainty of several meters [52]. This aspect, which needs to be considered for interpretation purposes, is related to the geometry of the SAR images and to the orbital tube, which directly impacts the precision of the topographic error. It is worth observing that the above uncertainty is at least three orders of magnitude larger than the uncertainty of the deformation estimates, which is a small fraction of the SAR wavelength, e.g., in the order of a few millimeters for C-band imagery.

Figure 2A illustrates this concept. The target is a warehouse located in the freight terminal of Livorno (Tuscany region, central Italy). This commercial area includes several buildings that show the evidences (cracks, foundations problems) of an ongoing subsidence phenomenon induced by the consolidation of highly compressible organic and clayey soils characterizing the subsurface of this area [53]. The A-DInSAR data are part of the Tuscany region monitoring system (see Section 2.6). Thirteen MPs are directly connected to the building. Other points are located in the vicinity of the structure, within a distance of $10 \mathrm{~m}$. The interpretation of such points is dual: they can be associated with the structure, since the distance is within the range of 3D geolocation accuracy of the technique, or they can be related to a coherent pixel which is part of the surrounding service area. A more precise geolocation would be ensured if a local scale data correction is performed, based on sub-pixel position analysis and with the support of external positioning data, e.g., ground control points or LiDAR point cloud $[54,55]$.
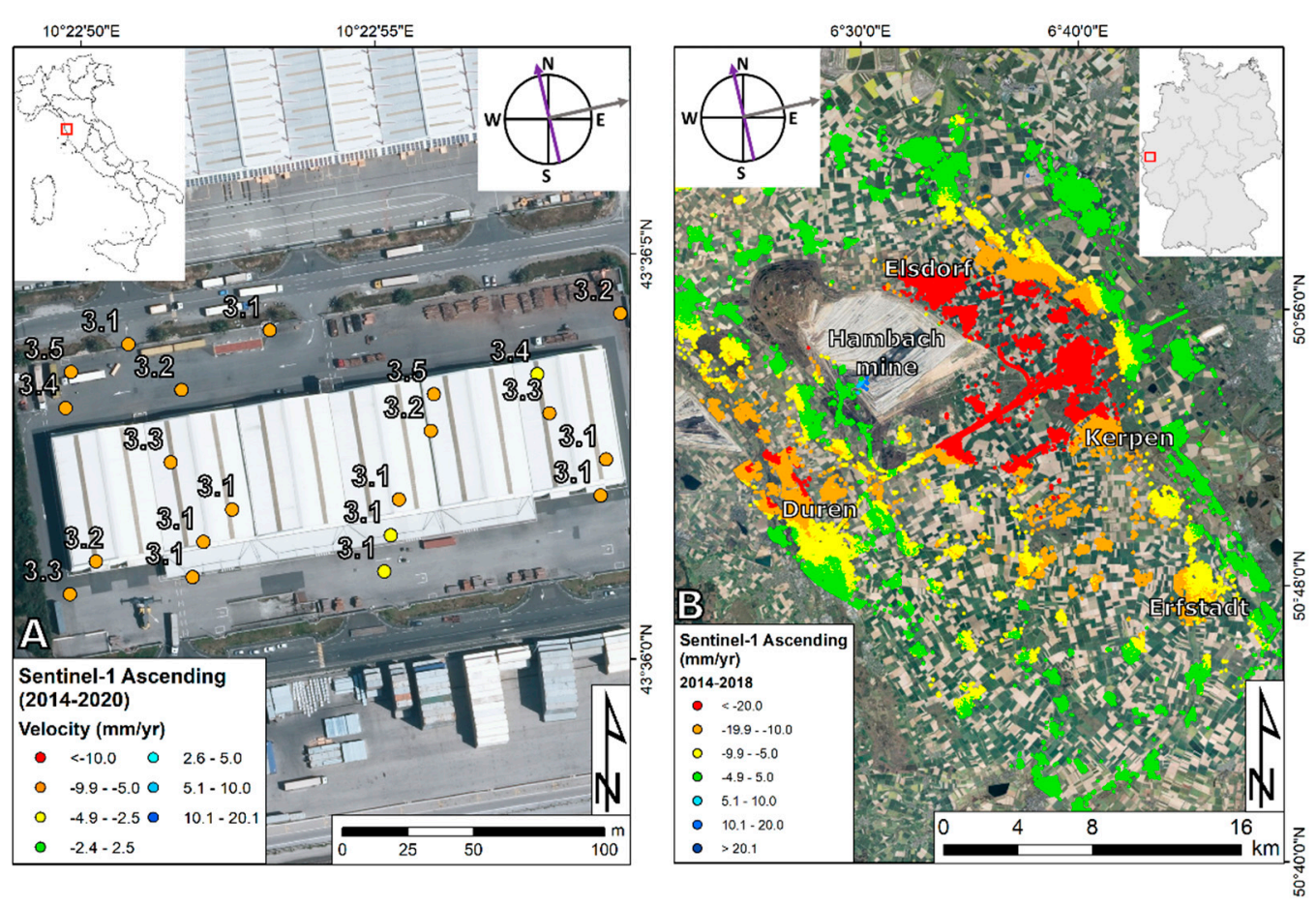

Figure 2. (A) Geolocation accuracy in the Livorno freight terminal, western Tuscany. Displayed numbers refer to the accuracy of the height estimation with respect to the reference DEM (in meters); (B) Mining-related subsidence in the North Rhine-Westphalia region, western Germany. Background image is an AGEA orthophoto 2016 for inset A and an ESRI World Imagery for inset B. 


\subsection{Observable Deformation Rates and Deformation Modeling}

Due to the ambiguous nature of the interferometric phases, A-DInSAR suffers severe limitations in the capability to measure fast deformation phenomena. The maximum differential deformation rate measurable with Sentinel- 1 is $85.2 \mathrm{~cm} / \mathrm{yr}$ ( $\lambda / 4$ every 6 days, where $\lambda$ is the wavelength). Note that this limit concerns differential rates, i.e., rates computed over pairs of MPs. The capability to measure a given deformation depends on its spatial pattern and the available MP density [2]. Many A-DInSAR approaches, e.g., those adopted in the GMSs, assume a linear deformation model in their processing. This assumption can negatively impact the estimation of nonlinear deformation phenomena: there can be a lack MPs in nonlinear motion areas, where a misfit between the linear model and the observed (nonlinear) deformation occurs. It is worth noting that some A-DInSAR approaches do not use a linear deformation model, e.g., see [56,57].

Figure 2B shows an example of mining-related subsidence which is useful to visualize how the density of MPs can be affected and limited by the presence of significant surface changes. The area of interest is located in western Germany, in the North Rhine-Westphalia region. The target is the Hambach open-pit coal mine and its surroundings. The mining activity has a high environmental impact in terms of deforestation, biodiversity and groundwater circulation. In particular, the increasing depth of the excavation activities makes the depletion of the ground water level necessary to guarantee the excavation of the coal basin [58]. The interferometric results provided by the German GMS evidence a large subsidence area, almost 20-km-wide and 25-km-long (Figure 2B). The data are acquired in ascending orbit and the LOS velocities range between $-50 \mathrm{~mm} / \mathrm{yr}$ in the vicinity of the mine to $-5 \mathrm{~mm} / \mathrm{yr}$ $20 \mathrm{~km}$ far from the mine. The presence of this subsidence area can be interpreted as evidence of the ground water level depression induced by the mining activity. It is important to notice that the active mining area contains just a few MPs because of the decorrelation due to the frequent surface changes induced by the excavation of new coal levels. This is typical for open pit mines. Another common source of decorrelation in mining areas in general is phase aliasing due to the presence of very high and nonlinear, displacement rates. Such motions cannot be captured without setting up of an ad hoc processing approach based on a nonlinear or hybrid deformation model.

\subsection{Monodimensional Nature of Deformation Measurements}

The A-DInSAR deformation measurements refer to the radar LOS, i.e., the line that connects the sensor and the target at hand. This is an important limitation of the technique: given a generic 3D deformation, A-DInSAR only provides the estimate of one component of such deformation, which is obtained by projecting the $3 \mathrm{D}$ deformation into the LOS direction. A serious improvement can be achieved when ascending and descending SAR data are available. In this case a $2 \mathrm{D}$ deformation estimation (the vertical component and the east-west horizontal one) can be retrieved, e.g., see [59], even if with loss of precision because of interpolation noises. This requires an independent processing of the ascending and descending datasets.

Figure 3 presents an example of the geometric LOS effects. It refers to the northern part of Norway, $40 \mathrm{~km}$ south of the city of Tromsø. The area is located in the most inland portion of the Ullsfjorden, which is a SW-NE-oriented fjord. It is 3-km-wide in this inland portion characterized by steep slopes with ridges higher than $1000 \mathrm{~m}$. The incised valleys of the fjords are highly prone to landslides [60]. In this case, both the east ("Siedi landslide") and west-facing ("Piggtind1 landslide") flanks of the fjords are affected by two large landslides, whose activity is revealed by the Norwegian GMS. The slopes are characterized by the presence of widespread moraine and slope deposits [61]. 

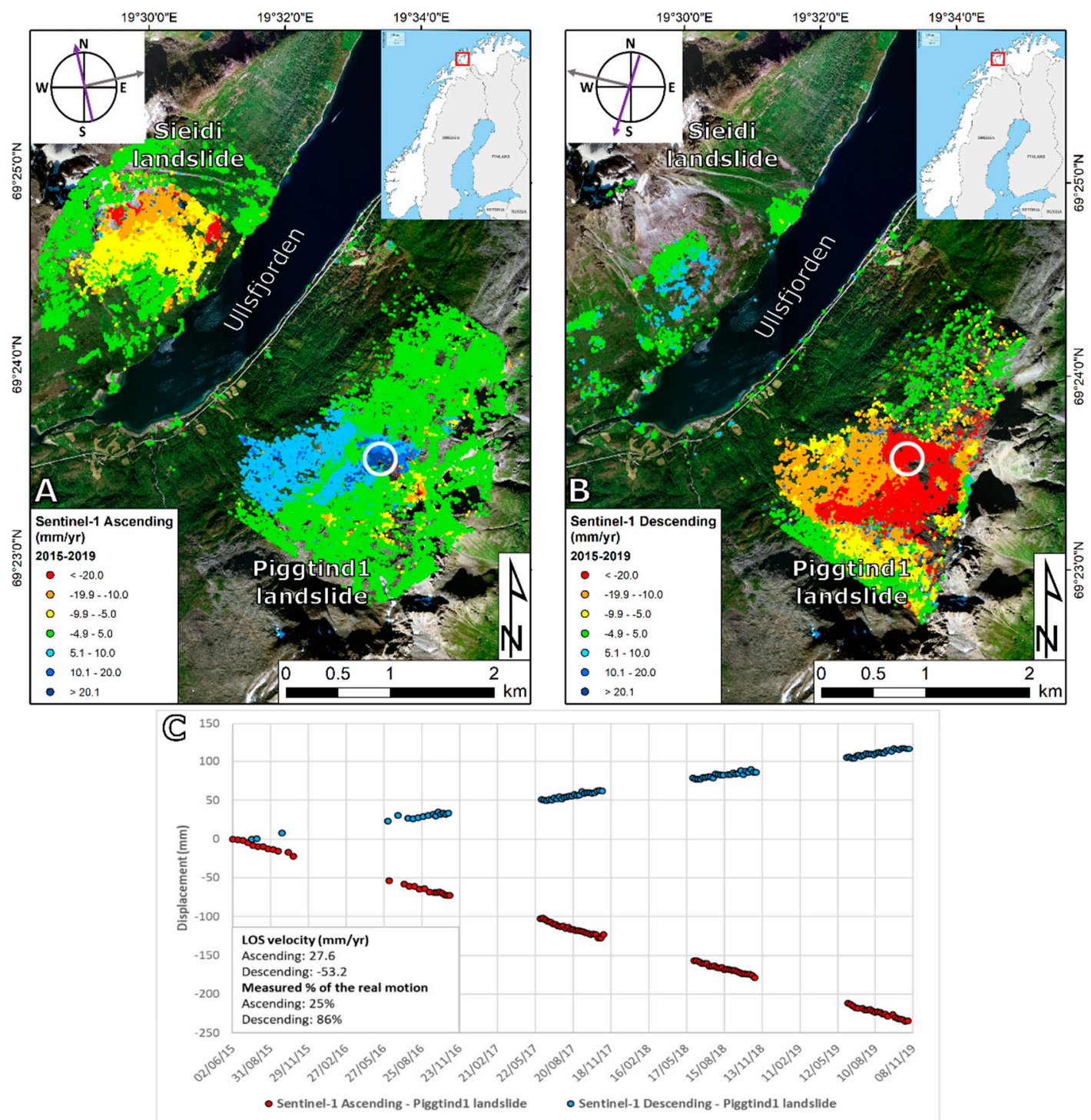

Figure 3. Two landslides along the Ullsfjorden (northern Norway) as captured by InSAR Norway data in (A) ascending and (B) descending orbits. (C) Time series are referred to the central portion of the Piggtind1 landslide. The background image for insets A and B is an ESRI World Imagery.

The A-DInSAR data well define the spatial characteristics of the two moving areas, with LOS velocities up to $50-70 \mathrm{~mm} / \mathrm{yr}$ for both landslides. The velocities are coherent with a movement along the slope with sign depending on the orbit, e.g., the Siedi landslide in ascending orbit has negative velocity, consistent with a movement away from the sensor. This example is useful to highlight:

- The different point coverage with respect to the geometry of acquisition. Foreshortening and layover effects [1] can compromise the detection of suitable pixels to be selected as measurement points. This is the case of the Siedi landslide in descending orbit (Figure 1B);

- The difference of velocity and displacement between orbits, see the time series extracted for the central portion of the Piggtind1 landslide in Figure 3C. There is a difference of ca. $30 \mathrm{~mm} / \mathrm{yr}$ between the velocities registered in ascending and descending orbits. Because of the geometry of the slope with respect to the LOS, the descending orbit can measure $88 \%$ of the along-slope motion, whereas the ascending orbit can estimate only the $25 \%$ of such component. These values were calculated following well-known geometric rules [59]. The underestimation of the along-slope component is common in A-DInSAR studies in mountainous areas (especially for $\mathrm{N}-\mathrm{S}$ valleys). 
The percentage of detectable motion affects the spatial pattern of the moving area as well. A low percentage implies a high probability to have measurement points falling within the stability range. This can produce misinterpretation of the results, if only one orbit is available.

\subsection{Low-Frequency Deformation Signals}

The A-DInSAR technique is a powerful tool to measure localized deformation. By contrast, it suffers limitations to capture low spatial frequency deformation signals, e.g., those in the scale from several tens of kilometers onwards. Examples of such signals can be those related to tectonic plate motion, or the postglacial uplift of Scandinavia. The reason is that the A-DInSAR low spatial frequency estimates are affected by uncompensated orbital errors or uncompensated low frequency atmospheric components that can mask the above signals. Any A-DInSAR application focused on low spatial-frequency deformation signals should consider this limitation. A way to overcome it is to fuse the A-DInSAR data with external information, e.g., see [62-65]. As it is described later, the main product of the EGMS is a GNSS-calibrated deformation map.

\section{The European Ground Motion Service}

This section concerns the EGMS initiative, the largest wide-area A-DInSAR service ever conceived. This initiative was defined in the period 2016-2017 by the so-called EGMS Task Force. The main characteristics of the EGMS were defined in the EGMS white paper, finalized in 2017 [13]. The same year, the Copernicus user forum and the Copernicus committee unanimously approved the addition of EGMS to the Copernicus land monitoring service's product portfolio [66]. The EGMS is to be implemented under the responsibility of the European Environment Agency [67]. Since 2019 this Agency is assisted by an external EGMS Advisory Board composed by European experts of A-DInSAR data analysis, interpretation and dissemination.

Furthermore, in the period from mid-2019 to the beginning of 2020, a consortium of A-DInSAR analysis experts made recommendations as regards the processing specifications for the EGMS and suggested ways of ensuring an efficient and effective implementation of the operational service. The generated documentation, which includes two main deliverables (the product specification document and the service implementation plan), is available online [52].

Some of the most important characteristics of the EGMS are briefly described below:

- The EGMS aims to provide consistent, updated, standardized, harmonized across national borders and reliable information regarding natural and anthropogenic ground motion phenomena over Europe.

- It will be based on Sentinel-1A and 1B SAR data. These data will be processed at full resolution.

- The EGMS will make use of the available Sentinel-1 acquisitions, i.e., two SAR images taken from two different look angles (ascending and descending), with a revisit time of six days.

- The ground motion will be estimated using an A-DInSAR approach aimed to derive deformation maps and time series.

- For all the regions affected by seasonal snow cover, the processing will be restricted to the snow-free scenes. This represents a limitation for the complete motion retrieval of such areas.

- The EGMS will produce a baseline product, which is composed of all the Sentinel-1 images from February 2015 to the start of data processing, followed by product updates every 12 months.

- A total of 750 single look complex (SLC) scenes cover Europe in ascending and descending orbit ( $\sim 20^{\prime} 000$ bursts). On average 260 scenes are available for each stack for the baseline product. This leads to a total input volume to produce the EGMS baseline equal to $\sim 1.5 \mathrm{~PB}$ of uncompressed SLC images. Every year, the volume will increase by 350 TB.

- The EGMS will be a highly demanding project in terms of computational capacity. The computing nodes will require high tier technical specifications in terms of central processing unit, random access memory and internal storage. 
- The production of the baseline of the EGMS will last for around one year. Up to six months will be needed to set up the processing system and interface, followed by 4 months of data processing. The production of the baseline is expected to be complete in the last quarter of 2021. Then, the service will be updated on an annual basis to guarantee its continuity over time.

\section{EGMS Products and Management}

The EGMS will include three main products:

- The first product is Level 2a, which includes deformation maps and deformation time series with measurements along the radar LOS. This is the basic EGMS product, which will be delivered for individual and consistent frames of the original SAR image stacks. The MPs will be referred to reference points, one for each frame. Level 2a products will be generated at full Sentinel-1 resolution.

- The second product is Level $2 \mathrm{~b}$. This is an advanced product, where the frames of Level 2a will all be mosaicked. It will consist in an A-DInSAR deformation map combined with a reference GNSS network. The deformation will refer to the radar LOS. The generation of this product will have to overcome the uneven availability of GNSS data across Europe. Level $2 \mathrm{~b}$ will be generated at full Sentinel-1 resolution.

- The third product is Level 3. This represents a more advanced product, especially with respect to Level 2a. It will include two main deformation components: the horizontal east-west and up-down vertical deformation. The input deformation map is Level $2 b$. Level 3 will be obtained by combining, at a coarser resolution $(100 \times 100 \mathrm{~m})$ with respect to the resolution of the Level $2 \mathrm{~b}$, the ascending and descending A-DInSAR results.

A simplified flowchart of the EGMS processing is depicted in Figure 4 along with a visual sketch of the three product levels. The representation of Level 2a is based on a random simulation of MP and reference points over Europe. The different colors for the tracks testify the independence of the frames, each one with its own reference. The EUREF permanent network [68] is used to simulate the reference GNSS network for the production of Level $2 b$; in this case the Sentinel-1 tracks are depicted in a common color to represent the harmonization of the frames. The resampling grid for Level 3 in Figure 4 is exaggerated for the sake of visualization.

The quality and reliability of the EGMS product is a priority. For this purpose, the production phase will include appropriate quality control and verification procedures. Specific quality requirements will be set for each product level, according to the technical capability and limitations of wide area A-DInSAR. In addition to this, an external validation team will perform the independent validation of the three main EGMS products.

The EGMS products will be made accessible through a dedicated dissemination platform. The data will be free and open, following the Copernicus open data policy. The EGMS will provide tools for the visualization, the interactive data exploration and the preliminary analysis of the service products. There will be specific tools for expert and non-experts and a dedicated API.

In addition, material to facilitate the user uptake will be distributed, which will include for instance protocols and best practice examples. In addition, different types of guidelines will be published. The user uptake will be facilitated through the organization of European, national and regional workshops and training sessions dedicated to the EGMS.

A non-exhaustive list of potential EGMS users include: geological and geophysical surveys; geodetic and topographic surveys; civil protection authorities; road and railway administrations; water management authorities; cultural heritage institutions; public authorities at European, national, regional and municipal levels; mining industry; oil and gas industry; engineering companies; insurance industry; research centers and universities; citizens. 

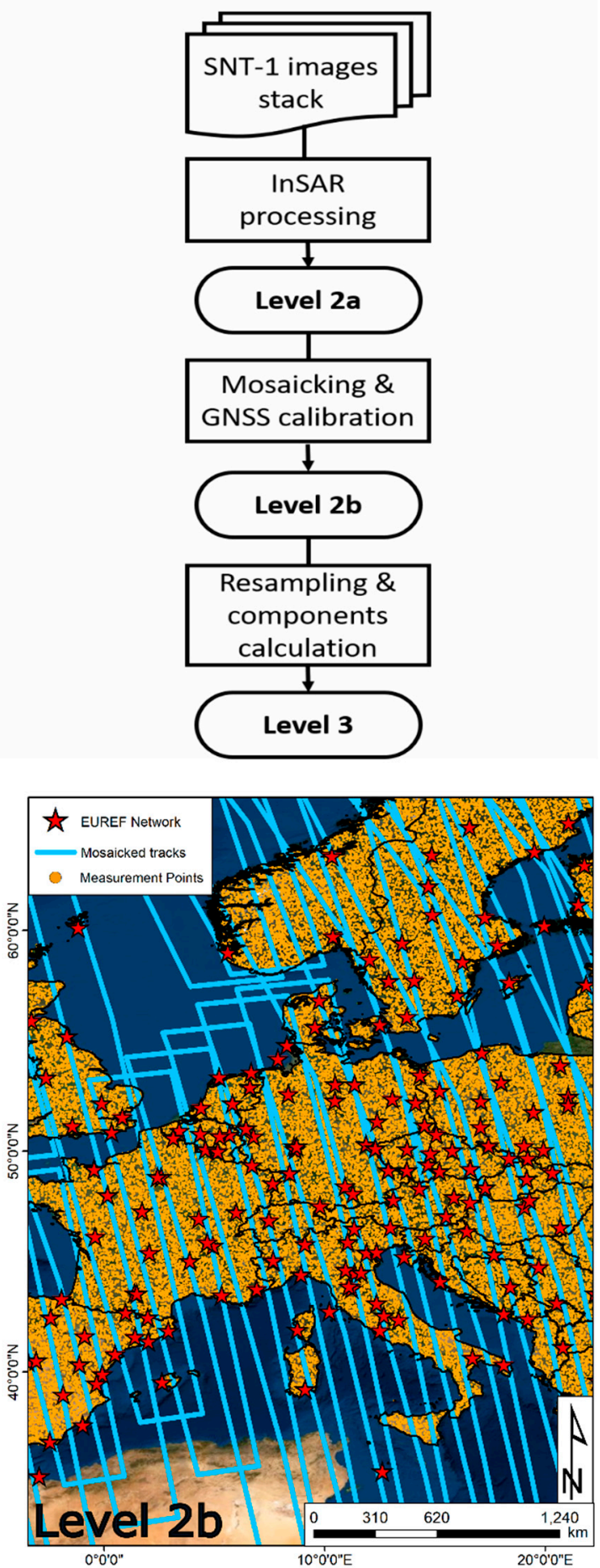
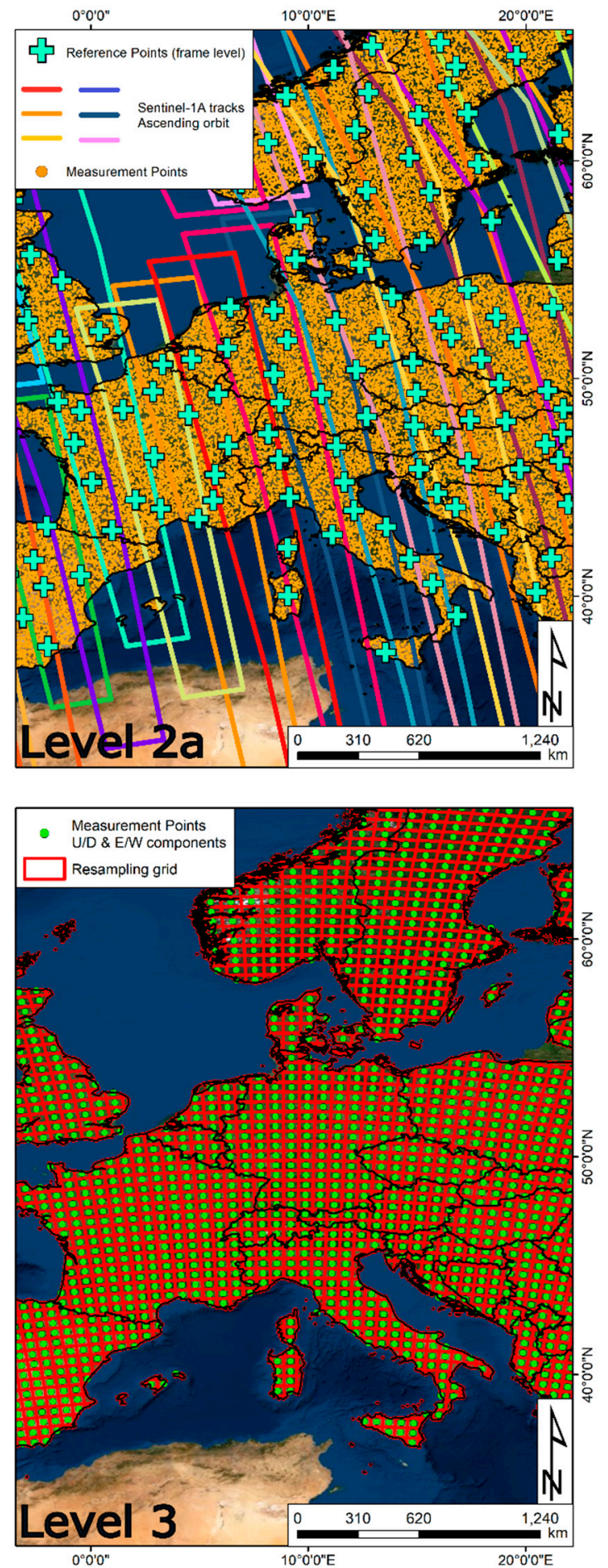

Figure 4. Simplified flowchart of the EGMS (upper left). Schematic representation of the EGMS Level 2a (upper right), of the Level $2 \mathrm{~b}$ (bottom left) and the Level 3 (bottom right) products. A snapshot of central Europe is offered (the maps are not depicting the full coverage of the EGMS).

\section{Conclusions}

The A-DInSAR techniques have undergone a dramatic development in the last twenty years. In the context of this study, the most important result of such a development is the capability to process big sets of SAR images, thus realizing wide-area A-DInSAR monitoring projects. 
In Europe, there are several initiatives to establish wide-area GMSs. The study describes the most important country-wide and region-wide A-DInSAR deformation monitoring services of Europe. Norway, Germany and Denmark have finalized their GMS based on Sentinel-1 images. Netherlands is finalizing its implementation. In Italy as a national GMS is still under implementation, three regions have already established their GMSs. Other European countries are discussing, developing or testing their GMSs.

Furthermore, the study reviews some of the most important technical aspects related to the A-DInSAR methodologies, giving emphasis to the aspects relevant to wide-area deformation monitoring. The key elements to be considered while using the products of the GMSs are summarized. Some of these technical aspects were discussed using data coming from existing GMSs.

The last section of the study is devoted to the EGMS, which is part of the Copernicus land monitoring service. The three main products of EGMS were outlined and the most important characteristics and key components of the service were described.

Some conclusions of this study are briefly listed below:

- In Europe, there is a clear trend towards the establishment of wide-area GMSs based on Sentinel-1 data and A-DInSAR techniques. Some of the GMSs are already operational. This demonstrates the feasibility of such services;

- The great majority of the GMSs grant free and open access to the A-DInSAR results;

- The EGMS represents the most important wide-area A-DInSAR deformation monitoring system ever developed;

- For the first time European countries will have access to pan-European free and standardized and quality assured A-DInSAR results;

- The EGMS is a great opportunity to increase the knowledge and use of A-DInSAR results in countries where availability and use of such data are limited or just emerging;

- The EGMS will allow the nations/regions running a GMS to diversify their activities, e.g., by processing very high-resolution radar images (X-band) or increasing the temporal frequency of release of the service products or providing other value-added products;

- The development of national and regional GMS should be coordinated as much as possible with the EGMS, also for reasons of economies of scale. All the GMSs and especially the EGMS, need to reach as many end users as possible. For this reason, attention must be paid to facilitate: The access and exploitation of the products of different GMSs, the user acceptability and user uptake; Note that these objectives involve both expert and non-expert users;

- It is expected that the EGMS is going to stimulate the development of downstream activities and of new tools and procedures to exploit the EGMS results;

- The success of the service will strengthen the role of A-DInSAR as a reliable ground monitoring technique.

Author Contributions: Conceptualization and writing, M.C., L.S.; national ground motion services, J.B.-L., M.F., A.O., D.A.M., L.G., V.C.; regional ground motion service, N.C.; review and homogenization, M.M., L.B., H.S.A. All authors have read and agreed to the published version of the manuscript.

Funding: This research received no external funding,

Acknowledgments: This work was partially funded by the Spanish Ministry of Economy and Competitiveness through the DEMOS project "Deformation monitoring using Sentinel-1 data" (Ref: CGL2017-83,704-P). This work has also been partially funded by the European Environment Agency through the project "Copernicus European ground motion service-Supporting Services" (Project n 3436/RO-COPERNICUS/EEA.57704).

Conflicts of Interest: The authors declare no conflicts of interest.

\section{References}

1. Hanssen, R. Radar Interferometry: Data Interpretation and Error Analysis; Kluwer Academic Publishers: Dordrecht, The Netherlands, 2001; pp. 1-307. 
2. Crosetto, M.; Monserrat, O.; Cuevas-González, M.; Devanthéry, N.; Crippa, B. Persistent Scatterer Interferometry: A review. ISPRS J. Photogramm. Remote Sens. 2016, 115, 78-89. [CrossRef]

3. Pepe, A.; Calò, F. A review of interferometric synthetic aperture RADAR (InSAR) multi-track approaches for the retrieval of Earth's surface displacements. Appl. Sci. 2017, 7, 1264. [CrossRef]

4. Torres, R.; Snoeij, P.; Geudtner, D.; Bibby, D.; Davidson, M.; Attema, E.; Potin, P.; Rommen, B.; Floury, N.; Brown, M.; et al. GMES Sentinel-1 mission. Remote Sens. Environ. 2012, 120, 9-24. [CrossRef]

5. Showstack, R. Sentinel Satellites initiate new Era in Earth Observation. Eos 2014, 26, 239-240. [CrossRef]

6. Ferretti, A.; Prati, C.; Rocca, F. Nonlinear subsidence rate estimation using permanent scatterers in differential SAR interferometry. IEEE Trans. Geosci. Remote Sens. 2000, 38, 2202-2212. [CrossRef]

7. Ferretti, A.; Prati, C.; Rocca, F. Permanent scatterers in SAR interferometry. IEEE Trans. Geosci. Remote Sens. 2001, 39, 8-20. [CrossRef]

8. Zinno, I.; Mossucca, L.; Elefante, S.; De Luca, C.; Casola, V.; Terzo, O.; Casu, F.; Lanari, R. Cloud computing for earth surface deformation analysis via spaceborne radar imaging: A case study. IEEE T. Cloud Comput. 2015, 4, 104-118. [CrossRef]

9. De Luca, C.; Zinno, I.; Manunta, M.; Lanari, R.; Casu, F. Large areas surface deformation analysis through a cloud computing P-SBAS approach for massive processing of DInSAR time series. Remote Sens. Environ. 2017, 202, 3-17. [CrossRef]

10. Adam, N.; Rodriguez-Gonzalez, F.; Parizzi, A.; Liebhart, W. Wide area persistent scatterer interferometry. In Proceedings of the 2011 Geoscience and Remote Sensing Symposium (IGARSS 2011), Vancouver, BC, Canada, 24-29 July 2011.

11. Manunta, M.; De Luca, C.; Zinno, I.; Casu, F.; Manzo, M.; Bonano, M.; Fusco, A.; Pepe, A.; Onorato, G.; Berardino, P.; et al. The Parallel SBAS Approach for Sentinel-1 Interferometric Wide Swath Deformation Time-Series Generation: Algorithm Description and Products Quality Assessment. IEEE Trans. Geosci. Remote Sens. 2019, 57, 6259-6281. [CrossRef]

12. Lanari, R.; Bonano, M.; Buonanno, S.; Casu, F.; De Luca, C.; Fusco, A.; Manunta, M.; Manzo, M.; Onorato, G.; Zeni, G.; et al. Continental scale SBAS-DInSAR processing for the generation of Sentinel-1 deformation time series within a cloud computing environment: Achieved results and lessons learned. In Proceedings of the EGU General Assembly 2020, Wien, Austria, 3-8 May 2020. [CrossRef]

13. EGMS White Paper. Available online: https://land.copernicus.eu/user-corner/technical-library/egms-whitepaper (accessed on 27 April 2020).

14. Costantini, M.; Falco, S.; Malvarosa, F.; Minati, F. A new method for identification and analysis of persistent scatterers in series of SAR images. In Proceedings of the IGARSS 2008-2008 IEEE International Geoscience and Remote Sensing Symposium, Boston, MA, USA, 8-11 July 2008; IEEE: Piscataway, NJ, USA, 2008; p. II-449.

15. Ferretti, A.; Fumagalli, A.; Novali, F.; Prati, C.; Rocca, F.; Rucci, A. A new algorithm for processing interferometric data-stacks: SqueeSAR. IEEE Trans. Geosci. Remote Sens. 2011, 49, 3460-3470. [CrossRef]

16. Costantini, M.; Ferretti, A.; Minati, F.; Falco, S.; Trillo, F.; Colombo, D.; Novali, F.; Malvarosa, F.; Mammone, C.; Vecchioli, F.; et al. Analysis of surface deformations over the whole Italian territory by interferometric processing of ERS, Envisat and COSMO-SkyMed radar data. Remote Sens. Environ. 2017, 202, 250-275. [CrossRef]

17. WebGIS of the PST-A Project. Available online: http://www.pcn.minambiente.it/viewer/ (accessed on 28 February 2020).

18. Guidelines for the Correct Interpretation of the Interferometric Products of the PST-A Project. Available online: http://www.pcn.minambiente.it/mattm/progetto-pst-prodotti-interferometrici/ (accessed on 28 February 2020).

19. Di Martire, D.; Paci, M.; Confuorto, P.; Costabile, S.; Guastaferro, F.; Verta, A.; Calcaterra, D. A nation-wide system for landslide mapping and risk management in Italy: The second Not-ordinary Plan of Environmental Remote Sensing. Int. J. Appl. Earth Obs. 2017, 63, 143-157. [CrossRef]

20. Italian Space Economy Strategic Plan. Available online: https://www.mise.gov.it/index.php/it/impresa/ competitivita-e-nuove-imprese/space-economy (accessed on 15 May 2020). (In Italian) 
21. Dehls, J.F.; Fischer, L.; Böhme, M.; Saintot, A.; Hermanns, R.H.; Oppikofer, T.; Lauknes, T.R.; Larsen, Y.; Blikra, L.H. Landslide monitoring in western Norway using high resolution TerraSAR-X and Radarsat-2 InSAR. In Landslides and Engineered Slopes: Protecting Society through Improved Understanding; Eberhardt, E., Froese, C., Turner, K., Leroueil, S., Eds.; Taylor \& Francis Group: London, UK, 2012; Volume 1, pp. 1321-1325.

22. Dehls, J.F.; Larsen, Y.; Marinkovic, P.; Lauknes, T.R.; Stødle, D.; Moldestad, D.A. INSAR.No: A National Insar Deformation Mapping/Monitoring Service In Norway-From Concept To Operations. In IGARSS 2019-2019 IEEE International Geoscience and Remote Sensing Symposium, 28 July-2 August 2019, Yokohama, Japan; IEEE: Piscataway, NJ, USA, 2019; pp. 5461-5464.

23. InSAR Norway WebGIS. Available online: https://insar.ngu.no/ (accessed on 3 March 2020).

24. Frequently Asked Questions Regarding InSAR Norway. Available online: https://www.ngu.no/en/topic/ frequently-asked-questions (accessed on 23 March 2020).

25. InSAR Norway Data Guidelines. Available online: https://www.ngu.no/en/topic/about-mapping-service (accessed on 23 March 2020).

26. Kalia, A.C.; Frei, M.; Lege, T. A Copernicus downstream-service for the nationwide monitoring of surface displacements in Germany. Remote Sens. Environ. 2017, 202, 234-249. [CrossRef]

27. Goel, K.; Adam, N.; Shau, R.; Rodriguez-Gonzalez, F. Improving the reference network in wide-area persistent scatterer interferometry for non-urban areas. In Proceedings of the 2016 IEEE International Geoscience and Remote Sensing Symposium (IGARSS), Beijing, China, 10-15 July 2016; pp. 1448-1451.

28. Adam, N. Methodology of a Troposphere Effect Mitigation Processor for SAR Interferometry. IEEE J. Sel. Top. Appl. Earth Obs. Remote Sens. 2019, 12, 5334-5344. [CrossRef]

29. Wendleder, A.; Felbier, A.; Wessel, B.; Huber, M.; Roth, A. A method to estimate long-wave height errors of SRTM S-band DEM. IEEE Geosci. Remote Sens. Lett. 2016, 13, 696-700. [CrossRef]

30. Jahn, C.H.; Riecken, J.; Trautvetter, C.; Freitag, M.; Kurtenbach, E.; Fabian, G.; Dick, H.G. Quo vadis SAPOS?-Zukünftige Entwicklungen des Positionierungsdienstes der Landesvermessung. Available online: https:/geodaesie.info/sr/gnss-2017-kompetenz-fuer-die-zukunft/6245/80 (accessed on 13 May 2020). (In German)

31. German Ground Motion Service WebGIS. Available online: https://bodenbewegungsdienst.bgr.de/ (accessed on 3 March 2020).

32. German Ground Motion Service (BodenBewegungsdienst Deutschland), Guidelines and InSAR Theory. Available online: https:/www.bgr.bund.de/DE/Themen/GG_Fernerkundung/Downloads/nutzungshinweisebbd-webgis.pdf?_blob=publicationFile\&v=3 (accessed on 23 March 2020). (In German)

33. German Ground Motion Service, Terms of Use. Available online: https:/www.geozentrumhannover.de/gzh/ DE/Impressum/datenschutzerklaerung.html (accessed on 23 March 2020). (In German)

34. Bischoff, C.A.; Ferretti, A.; Novali, F.; Uttini, A.; Giannico, C.; Meloni, F. Nationwide deformation monitoring with SqueeSAR ${ }^{\circledR}$ using Sentinel-1 data. In Proceedings of the Tenth International Symposium on Land Subsidence, Delft-Gouda, The Netherlands, 20-24 April 2020; p. 31382.

35. Weber, M. SDFEs Permanente GNSS-Stationer: Beregning af nye ETRS89-Koordinater; Agency for Data Supply and Efficiency: Copenhagen, Denmark, 2019. (In Danish)

36. Knudsen, P. Dokumentation for Beregning af ny Uplift-Model 2016; DTU Space, Technical University of Denmark: Copenhagen, Denmark, 2016. (In Danish)

37. Baltink, H.K.; Van Der Marel, H.; Van der Hoeven, A.G. Integrated atmospheric water vapor estimates from a regional GPS network. J. Geophys. Res. Atmos. 2002, 107, ACL-3. [CrossRef]

38. Lesparre, J. The impact of the antenna mounting on the phase centre variation. In Proceedings of the EUREF Symposium, Riga, Latvia, 14-17 June 2006; pp. 3-5.

39. Wouters, W.; Bollweg, A. A Detailed Elevation Model Using Airborne Laser Altimetry. Geod. Info. Mag. 1998, 9, 6-9.

40. Mahapatra, P.; Van der Marel, H.; Van Leijen, F.; Samiei-Esfahany, S.; Klees, R.; Hanssen, R. InSAR datum connection using GNSS-augmented radar transponders. J. Geod. 2018, 92, 21-32. [CrossRef]

41. Raspini, F.; Bianchini, S.; Ciampalini, A.; Del Soldato, M.; Solari, L.; Novali, F.; Del Conte, S.; Rucci, A.; Ferretti, A.; Casagli, N. Continuous, semi-automatic monitoring of ground deformation using Sentinel-1 satellites. Sci. Rep. 2018, 8, 1-11. [CrossRef]

42. Tuscany Region WebGIS. Available online: https://geoportale.lamma.rete.toscana.it/difesa_suolo/\#/viewer/ openlayers/326 (accessed on 20 March 2020). 
43. Interferometric Data Guidelines (In Italian). Available online: https://www.regione.toscana.it/documents/ 10180/14985922/Linee+guida+per+1\%E2\%80\%99utilizzo+dei+dati+interferometrici+del+geoportale.pdf/ d5b091a7-a5b1-41e9-97c3-270a52b0c7ce (accessed on 20 March 2020).

44. Interferometric Data Disclaimer (In Italian). Available online: https://www.regione.toscana.it/documents/ 10180/14985922/Termini+di+utilizzo+dei+dati+del+geoportale.pdf/76d8b222-f2fc-489e-91f7-fb25fb6e86f4 (accessed on 20 March 2020).

45. Del Soldato, M.; Solari, L.; Raspini, F.; Bianchini, S.; Ciampalini, A.; Montalti, R.; Ferretti, A.; Pellegrineschi, V.; Casagli, N. Monitoring Ground Instabilities Using SAR Satellite Data: A Practical Approach. ISPRS Int. J. Geoinf. 2019, 8, 307. [CrossRef]

46. Raspini, F.; Bianchini, S.; Ciampalini, A.; Del Soldato, M.; Montalti, R.; Solari, L.; Tofani, V.; Casagli, N. Persistent Scatterers continuous streaming for landslide monitoring and mapping: The case of the Tuscany region (Italy). Landslides 2019, 16, 2033-2044. [CrossRef]

47. Eriksen, H.Ø.; Lauknes, T.R.; Larsen, Y.; Corner, G.D.; Bergh, S.G.; Dehls, J.; Kierulf, H.P. Visualizing and interpreting surface displacement patterns on unstable slopes using multi-geometry satellite SAR interferometry (2D InSAR). Rem. Sens. Environ. 2017, 191, 297-312. [CrossRef]

48. Lanari, R.; Mora, O.; Manunta, M.; Mallorquí, J.J.; Berardino, P.; Sansosti, E. A small-baseline approach for investigating deformations on full-resolution differential SAR interferograms. IEEE Trans. Geosci. Remote Sens. 2004, 42, 1377-1386. [CrossRef]

49. Hooper, A. Persistent Scatterer Radar Interferometry for Crustal Deformation Studies and Modeling of Volcanic Deformation. Ph.D. Thesis, Stanford University, Stanford, CA, USA, 2006.

50. Hooper, A. A multi-temporal InSAR method incorporating both persistent scatterer and small baseline approaches. Geophys. Res. Lett. 2008, 35. [CrossRef]

51. Corine Land Cover 2018 Data Access Platform. Available online: https://land.copernicus.eu/pan-european/ corine-land-cover/clc2018 (accessed on 12 April 2020).

52. Larsen, Y.; Marinkovic, P.; Dehls, J.F.; Bredal, M.; Bishop, C.; Jøkulsson, G.; Gjøvik, L.P.; Frauenfelder, R.; Salazar, S.; Vöge, M.; et al. European Ground Motion Service: Service Implementation. Copernicus Land Monitoring Service Report. 2020. Available online: https://land.copernicus.eu/user-corner/technical-library/ egms-specification-and-implementation-plan (accessed on 11 May 2020).

53. Ciampalini, A.; Solari, L.; Giannecchini, R.; Galanti, Y.; Moretti, S. Evaluation of subsidence induced by long-lasting buildings load using InSAR technique and geotechnical data: The case study of a Freight Terminal (Tuscany, Italy). Int. J. Appl. Earth Obs. 2019, 82, 101925. [CrossRef]

54. Yang, M.; López-Dekker, P.; Dheenathayalan, P.; Liao, M.; Hanssen, R.F. On the value of corner reflectors and surface models in InSAR precise point positioning. ISPRS J. Photogramm 2019, 158, 113-122. [CrossRef]

55. Van Natijne, A.L.; Lindenbergh, R.C.; Lindenbergh, R.C.; Hanssen, R.F. Massive linking of PS-InSAR deformations to a national airborne laser point cloud. Int. Arch. Photogramm. Remote Sens. Spat. Inf. Sci. 2018, 42, 1137-1144. [CrossRef]

56. Berardino, P.; Fornaro, G.; Lanari, R.; Sansosti, E. A new algorithm for surface deformation monitoring based on small baseline differential SAR interferograms. IEEE Trans. Geosci. Remote Sens. 2002, 40, 2375-2383. [CrossRef]

57. Devanthéry, N.; Crosetto, M.; Monserrat, O.; Cuevas-González, M.; Crippa, B. An Approach to Persistent Scatterer Interferometry. Remote Sens. 2014, 6, 6662-6679. [CrossRef]

58. Spiller, M.; Forkel, C.; Köngeter, J. Case study: Inflow of groundwater into open-cast mine Hambach, Germany. J. Hydraul. Eng. 2004, 130, 608-615. [CrossRef]

59. Notti, D.; Herrera, G.; Bianchini, S.; Meisina, C.; García-Davalillo, J.C.; Zucca, F. A methodology for improving landslide PSI data analysis. Int. J. Remote Sens. 2014, 35, 2186-2214. [CrossRef]

60. Hermanns, R.L.; Hansen, L.; Sletten, K.; Böhme, M.; Bunkholt, H.; Dehls, J.F.; Eilertsen, R.; Fischer, L.; L'Heureux, J.S.; Høgaas, F.; et al. Systematic geological mapping for landslide understanding in the Norwegian context. In Landslide and Engineered Slopes: Protecting Society through Improved Understanding; Eberhardt, E., Froese, C., Turner, K., Leroueil, S., Eds.; CRC Press: London, UK, 2012; Volume 2, pp. 265-271.

61. National Database of Superficial Deposits. Available online: http://geo.ngu.no/kart/losmasse_mobil/?lang= eng (accessed on 16 April 2020). 
62. Chen, Q.; Liu, G.; Ding, X.; Hu, J.C.; Yuan, L.; Zhong, P.; Omura, M. Tight integration of GPS observations and persistent scatterer InSAR for detecting vertical ground motion in Hong Kong. Int. J. Appl. Earth Obs. 2010, 12, 477-486. [CrossRef]

63. Hung, W.C.; Hwang, C.; Chen, Y.A.; Chang, C.P.; Yen, J.Y.; Hooper, A.; Yang, C.Y. Surface deformation from persistent scatterers SAR interferometry and fusion with leveling data: A case study over the Choushui River Alluvial Fan, Taiwan. Remote Sens. Environ. 2011, 115, 957-967. [CrossRef]

64. Caro Cuenca, M.; Hanssen, R.F.; Hooper, A.; Arikan, M. Surface Deformation of the Whole Netherlands After PSI Analysis. In Proceedings of the Fringe 2011 Workshop, Frascati, Italy, 19-23 September 2011; pp. 1-8.

65. Hanssen, R.F.; Caro Cuenca, M.; Klees, R.; Van der Marel, H. Decadal vertical deformation of the Netherlands via the geodetic integration of gravimetry, GNSS, leveling and SAR interferometry. In Proceedings of the American Geophysical Union Fall Meeting 2012 Abstracts, San Francisco, CA, USA, 3-7 December 2012.

66. Copernicus Land Monitoring Service Website. Available online: https://land.copernicus.eu/user-corner/ technical-library/european-ground-motion-service (accessed on 8 May 2020).

67. European Environment Agency Website. Available online: https://www.eea.europa.eu/about-us (accessed on 8 May 2020).

68. Bruyninx, C.; Habrich, H.; Söhne, W.; Kenyeres, A.; Stangl, G.; Völksen, C. Enhancement of the EUREF Permanent Network Services and Products. In Geodesy for Planet Earth; Springer: Berlin/Heidelberg, Germany, 2012; Volume 136, pp. 27-34.

(C) 2020 by the authors. Licensee MDPI, Basel, Switzerland. This article is an open access article distributed under the terms and conditions of the Creative Commons Attribution (CC BY) license (http://creativecommons.org/licenses/by/4.0/). 